\title{
Processing Russian inflectional morphology: A PET study of verb generation
}

Tatiana Chernigovskaya ${ }^{1}$, Kira Gor ${ }^{2}$, Galina Kataeva ${ }^{3}$, Alexander Korotkov $^{3}$, Maxim Kireev ${ }^{3}$, Kristina Memetova ${ }^{3}$, Svyatoslav Medvedev ${ }^{3}$

${ }^{1}$ St. Petersburg State University, Russia

${ }^{2}$ University of Maryland, USA

${ }^{3}$ The Institute of the Human Brain, Russian Academy of Sciences

https://doi.org/10.36505/ExLing-2011/04/0014/000183

\begin{abstract}
For many years, acquisition of verbal morphology has been an issue of much debate within linguistic theory, research on first and second language acquisition, mental grammar representation, and cognitive processing. The proponents of the Dual Mechanism account claim that regularly inflected forms are computed by a ruleprocessing system, while morphologically irregular forms are processed in associative memory. The opposite Single Mechanism account claims that both regular and irregular forms are processed in associative memory. In the present PET study significant $\mathrm{rCBF}$ increase in the anterior cingulate gyrus of the left hemisphere (24 BA) was shown for regular verb generation.This may support the rule-based (de)compositional account.
\end{abstract}

Key words: morphology, anterior cingulate cortex, error detection system

\section{Introduction}

For many years, acquisition of verbal morphology has been an issue of much debate within linguistic theory, research on first and second language acquisition, mental grammar representation, and cognitive processing. The "English past tense debate", which addresses the issue of "nature vs. nurture", explores whether the processing of regular and irregular morphology is driven by two distinct mechanisms, or by one single mechanism. The proponents of the Dual Mechanism account claim that regular forms are computed by a rule-processing system, while irregular morphological forms are processed in associative memory. The opposite view claims that both regular and irregular forms are processed in associative memory (see for discussion Chernigovskaya \& Gor, 2001; Gor 2010). Jaeger et al. (1996) has made an attempt to find the cerebral localization of regular vs. irregular English verb processing, with the data discussed in support of the Dual Mechanism account. However, Chandler \& Skousen (1997) published their own interpretation showing that Jaeger's results are not in conflict with the Single Mechanism Account.

The available brain-imaging data on regular/irregular verb generation are conflicting, which reflects the controversies in the state-of-the-art neurolinguistic data interpretation in (e.g., Demonet et al. 2005, Sidtis 2006).

ExLing 2011: Proceedings of 4th Tutorial and Research Workshop on Experimental Linguistics, 25-27 May, Paris, France 
This research suggests that being one of the basic brain mechanisms, the error-detection processor (Bechtereva et al., 1968, 2005) may be implicated in linguistic procedures - as it does with all the other cognitive tasks - from routine actions to arithmetic problem solving. Its function is to compare the current status with virtual templates and rules stored in memory. Following it a certain processing routine is chosen under appropriate circumstances.

Our approach predicts that if a verbal form is generated on the basis of a default template (regular forms) it should be automatically checked for rule adequacy, and thus the error detector will be activated. Conversely, if there is no difference between rule-based procedures and associative memory retrieval, its activation will take place in both cases. As the key area for this mechanism is anterior cingulate cortex (Mathalon et al., 2003), it was selected as the region of interest that will make it possible to distinguish between the two accounts.

The aim of the study was to reveal the level of functional activity in anterior cingulate cortex caused by the generation of regular/irregular verbs, nonce verbs, and plural of nouns.

\section{Methods}

\section{Subjects}

Twelve native right-handed Russian-speaking volunteers, age 22-29, provided written informed consent for participation in the study.

\section{Experimental task}

Stimuli (4 word lists in black letters on a white background) were presented at random on a color monitor $1,5 \mathrm{~m}$ from the nasion. The stimuli were: the $\mathrm{i}-$ class semi-regular verbs (warm-up), singular nouns (N), irregular verbs (I), the aj-class regular verbs $(\mathrm{R})$, the aj-class nonce verbs $(\mathrm{Q})$. During each of the four experimental conditions, subjects viewed the sequence of 65 words at a rate of one word every $2 \mathrm{~s}$, with exposure time from 80 to $160 \mathrm{~ms}$ with $1850 \mathrm{~ms}$ intervals. Subjects produced $1^{\text {st }}$ person singular past tense forms for verbs and plural forms for nouns. Participants were asked to perform each task continuously for approximately $135 \mathrm{~s}$, because a minimum of $90 \mathrm{~s}$ of stimulus data duration is required for acquiring a statistically valid image of brain activity.

\section{Data acquisition and analysis}

During PET scans the regional cerebral blood flow ( $\mathrm{rCBF}$ ) was measured with Scanditronix PC2048-15B PET-scanner; the standard protocol was described elsewhere (Kataeva \& Korotkov, 2007). PET data processing was performed with SPM8 and WFU Picatlas software (Maldjian et al., 2003). After spatial normalization of images, the mean $\mathrm{rCBF}$ was measured in four volumes of interest (VOIs) corresponding to Brodman areas (BA) 24 and 32 of left and right hemispheres. Differences in global flow were discarded by 
normalization for the mean acquired activity in the field of view (Arndt et al., 1996) and $\mathrm{rCBF}$ was expressed as percentages of mean global CBF. A repeated measures MANOVA was used for statistical analysis with the test conditions as within-subjects effect. The significance level was set at $\mathrm{p}=0.01$. The post-hoc analyses with $\mathrm{p}=0.01$ (Fisher LSD test) were used to assess the individual differences.

\section{Results and discussion}

The evaluation of rCBF found that the PET-condition with regular verbs generation was characterized by increased levels of regional cerebral blood flow in comparison with all the other conditions, within the volume of interest corresponding to 24 Brodmann area (BA) in the anterior cingulate gyrus of the left hemisphere: $\mathrm{R}>\mathrm{N}(\mathrm{p}<0,0004) ; \mathrm{R}>\mathrm{Q}(\mathrm{p}<0,0001)$ and $\mathrm{R}>\mathrm{I}$ $(\mathrm{p}<0.0009)$.

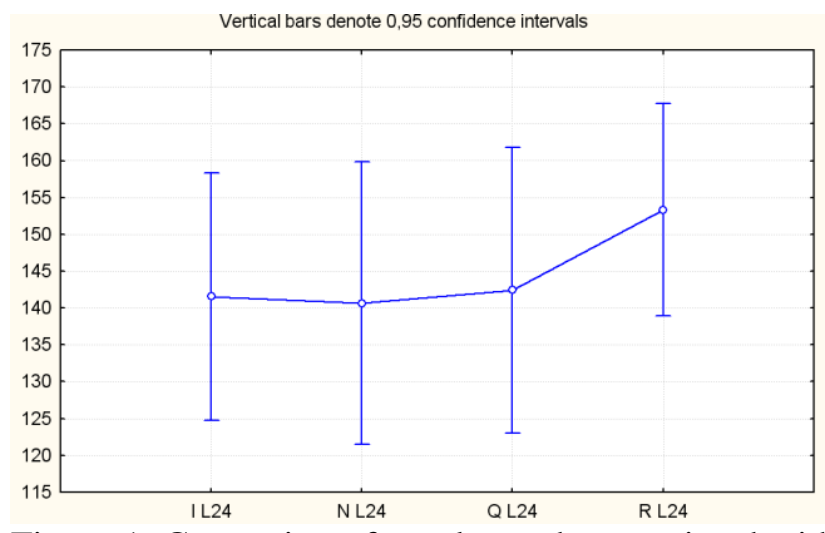

Figure 1. Generation of regular verbs associated with increased $\mathrm{rCBF}$ in left anterior cingulated cortex (BA 24). Notations: R- regular verb production; Iirregular verb production; $\mathrm{N}$ - noun production; $\mathrm{Q}$ - nonce verb production; $\mathrm{L}$ 24 - left BA 24.

A significant $\mathrm{rCBF}$ increase in the anterior cingulate gyrus of the left hemisphere (24 BA) was shown for regular verb generation in comparison with all the other conditions (irregular, nonce verbs, and nouns). These data indicate that left anterior cingulate cortex is an important brain area subserving the mechanism of regular verbal processing. This is consistent with the rule-based (de)compositional account: The error detector checks if the word matches the systematic and productive rules; it is not activated when the inflected forms are idiosyncratic. It might be argued that these findings are compatible with both the Dual and Single Mechanism accounts. And indeed, BA 24 activation cannot exclude the possibility of a unitary rule-based morphological mechanism for inflectional paradigms. Event- 
related fMRI imaging is a promising method to explore the relationship between regular and irregular verbal processing.

\section{Acknowledgements}

Grants from the Russian Ministry of Education and Science (\# 16.740.11.0113, 02.740.11.0369), RFRH (\# 10-04-00056a; 10-06-00726a), OBN RAS 2011.

\section{References}

Arndt, S., Cizadlo, T., O'Leary, D., Gold, S., Andreasen, N.C. 1996. Normalizing counts and cerebral blood flow intensity in functional imaging studies of the human brain. NeuroImage, 3, 175-184.

Bechtereva, N.P., Gretchin, V.B. 1968. Physiological foundations of mental activity. Int. Rev. Neurobiol., 11, 329-352

Bechtereva, N.P., Shemyakina, N.V., Starchenko, M.G., Danko, S.G., Medvedev, S.V. 2005. Error detectors mechanisms of the brain: background and prospects. Intern. J. of Psychophysiology, 58, 227-234.

Démonet, J.F., Thierry, G., Cardebat, D. 2005. Renewal of the neurophysiology of language: functional neuroimaging. Physiol Rev., 85, 49-95.

Chandler, S., Skousen, R. 1997. Analogical modeling and the English past tense: a reply to Jaeger et. al. 1996 <http://humanities.byu.edu/am/>

Chernigovskaya, T., Gor, K. 2001. The Complexity of Paradigm and Input Frequencies in Native and Second Language Verbal Processing: Evidence from Russian. Language and Language Behavior, 3 (II), 20-37.

Gor, K. 2010. Beyond the obvious: Do second language learners process inflectional morphology? Language Learning, 60.1, 1-20.

Jaeger, J., Lockwood, D., Kemmerer, R., Van Valin, R., Murphy, R., Kahlak, H. 1996. A positron emission tomography study of regular and irregular verb morphology in English. Language. 72. 451-497.

Kataeva, G.V. and Korotkov, A.D. 2007 The regional cerebral blood flow pattern of the normal human brain and its factor structure. Human Physiology, 33.4, 383-387

Maldjian, J.A., Laurienti, P.J., Kraft, R.A., Burdette, J.H., 2003. An automated method for neuroanatomic and cytoarchitectonic atlas-based interrogation of fmri data sets. NeuroImage, 19, 1233-1239.

Mathalon, D.H., Whitfield, S.L., Ford, J.M. 2003. Anatomy of an error: ERP and fMRI. Biolog. Psychol., 64, 119-141.

Sidtis D. 2006. Does functional neuroimaging solve the questions of neurolinguistics? Brain Lang., 98, 276-90. 